\title{
Arsitektur Pasar dan Manusia sebagai Penggerak Peradaban Kota
}

\author{
Rizky Maulana Ibrahim dan Angger Sukma Mahendra \\ Departemen Arsitektur, Fakultas Arsitektur Desain dan Perencanaan, \\ Institut Teknologi Sepuluh Nopember (ITS) \\ e-mail: angger@arch.its.ac.id
}

\begin{abstract}
Abstrak-Arsitektur dan manusia sama sekali tidak dapat dipisahkan. Meskipun arsitektur dibentuk oleh manusia sedemikian rupa, tetapi secara tidak sadar arsitektur juga membentuk dimensi berfikir dan pola berperilaku manusia itu sendiri. Mereka adalah sebuah paradoksial yang akan terus berlanjut, dimana arsitektur itu ada karena manusia dan manusia itu ada karena arsitektur. Hubungan mereka sangat sinergis dalam menciptakan suatu peradaban dimasa lampau yang dapat dirasakan saat ini, bahkan hingga masa mendatang. Namun keegoisan manusia dewasa ini, tidak lagi memperdulikan keberadaan arsitektur yang mempunyai pengaruh penting dalam kehidupan manusia. Sehingga arsitektur diciptakan hanya sekedar variabel fisik (alat guna), yang kemudian akan berdampak buruk dalam tatanan kehidupan sosial yang cenderung individualis. Bercermin dari semua itu, re-design Pasar Tradisional Puri Pati dengan pendekatan synomorphy adalah untuk memicu adanya interaksi antar pengguna dan bangunan. Adapun metode riset menggunakan behavior mapping untuk menganalisa data dan fakta-fakta yang terjadi pada lapangan melalui pemetaan perilaku dan metode perancangan menggunakan teori Architectural programing untuk mempermudah alur berfikir dalam menentukan permasalahan desain yang kemudian ditarik menjadi perwujudan kriteria konsep desain. Sehingga perancangan dapat menjadi triger dalam menciptakan keberadaan arsitektur yang akan mengembalikan harmonisnya kehidupan sosial yang arif dan humanis.
\end{abstract}

Kata Kunci-Arsitektur, Manusia, Pasar, Kota, Synomorphy.

\section{PENDAHULUAN}

A RSITEKTUR dan manusia adalah subjek utama dalam membentuk karakter kota. Berawal dari manusia dikatakan sebagai makhluk sosial karena adanya keharusan dan dorongan dalam bersosial atau berinteraksi dengan sesama maupun dengan lingkungan sekitarnya. Ini berguna bagi pembentukan karakter manusia baik berperilaku maupun berpikir [1]. Pembentukan karakter ini bila dilihat secara makro berpengaruh pada pembentukan budaya bermasyarakat dilingkup kecil desa-kota ataupun lingkup teritorial yang lebih luas. Tentunya hal ini membutuhkan ruang (millieu) yang mendukung dalam mengakomodir pola-pola pembentuk interaksi antar manusia, karena skala ruang mempengaruhi pembentukan perilaku manusia sebagai penggunanya. Begitupun sebaliknya perilaku manusia mempengaruhi suasana-kondisi ruang tersebut (synomorphy). (lihat Gambar $1)$.

\section{A. Hubungan skala ruang dan manusia}

Manusia merupakan pusat dari lingkungan, sekaligus menjadi bagian dari lingkungan itu sendiri [2]. Dengan hal ini dalam berinteraksi dengan ruang, seorang individu selain dipengaruhi oleh suasana ruang ia juga mempengaruhi suasana ruang itu sendiri. Ada timbal-balik yang terjadi (synomorphy).

Namun fenomenanya, kebanyakan desain arsitektur/ruang (millieu) hanya membagi kedua masing-masig variable tersebut secara berdiri sendiri (tidak terikat satu sama lain). Seakan variable manusia dipaksakan untuk merespon sebuah desain ruang yang terbentuk tanpa adannya pertimbangan pengguna, sehingga proses sosial yang terjadi tak selayak dan tak senormal dalam melahirkan konsep "behavior setting" di dalamnya. Seharusnya kualitas euphoria yang berbicara, bukan hanya dari kualitas fisik melainkan kesinambungan antar keduanya (synomorphy). Sehingga karakter sosial pada masyarakat semakin sirna keberadaannya, berdampak pula pada pola organisme kota. (lihat Gambar 2)

Jadi dengan menggerakkan perilaku manusia melalui sebuah arsitektur secara teratur akan meng-create pola kebiasaan manusia sebagai subjek, yang kemudian pola kebiasaan manusia secara komunal akan membentuk kebudayaan atau karakter lokal.

\section{B. Lingkup Perancangan: Pasar Tradisional}

Adapun tipologi arsitektur pasar tradisional dirasa paling berperan dalam pembentukan karakter kota, dimana ia adalah ruang sosial/publik terbesar dalam skala kota yang kental realisasinya akan proses interaksi. Namun seiring berkembangnya zaman terjadi perubahan tuntutan standar konsumen terhadap pasar tradisional, sehingga posisi pasar tradisional mulai tergantikan oleh pasar modern. Munculnya citra yang buruk terhadap pasar tradisional menjadi salah satu faktor yang membuat para pembeli enggan untuk mengunjungi pasar. Sehingga eksistensi dari pasar tradisional kian waktu mulai menurun.

Lambat laun kinerja pasar tradisional diakuisisi oleh pasar modern sebagai pembentuk karakter kota yang cenderung individualis. Karena pasar tradisional tak lagi mempunyai fasilitas yang cukup mengakomodasikan bentuk dari interaksi sosial, sehingga masyarakat cenderung memandang pasar tradisional dengan hanya sebelah mata sebagai tempat untuk sekedar membeli sesuatu berkebutuhan pokok, bukan lagi sebagai ruang sosial yang mempunyai potensi pembentuk karakter kota melalui diri perorangan.

\section{Pati sebagai Konteks}

Kondisi demikian terjadi pula pada pasar induk kab. Pati. Pati adalah kota kecil di Jawa Tengah yang mempunyai 3 julukan unik sebagai karakter kotanya, yakni: Pati kota Pensiunan, Pati kota Karaoke, Pati kota Paranormal. Ke-tiga 
hal ini yang menjadi respon utama penyelesaian karakter kota melalui tatanan fasilitas tambahan pada re-design pasar induk Pasar Tradisional Puri Pati. Dengan adanya respon melalui tatanan fasilitas diharapkan akan membangun karakter kota yang tidak berkonotasi negatif. (lihat Gambar 3,4,5)

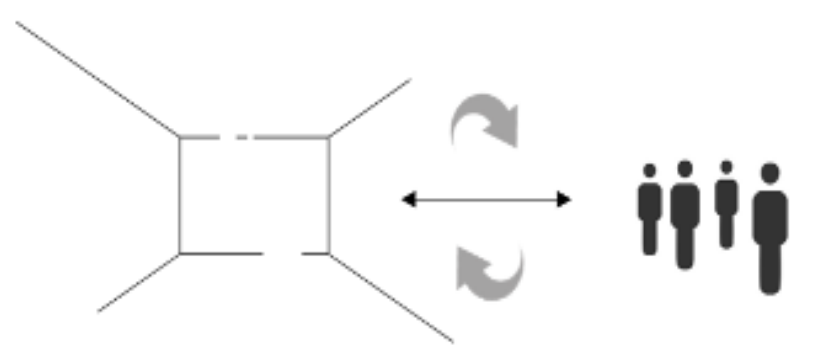

Gambar 1. Ilustrasi keterhubungan antara ruang dan manusia.

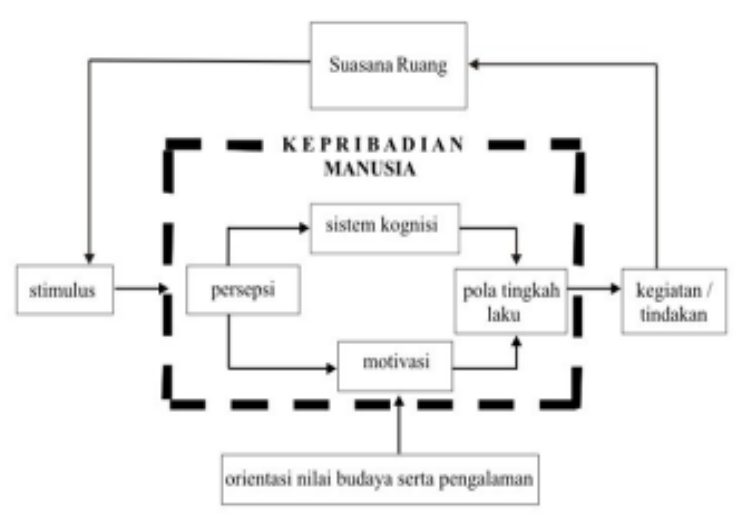

Gambar 2. Proses psikologis interaksi manusia terhadap lingkungan (millieu). [3].

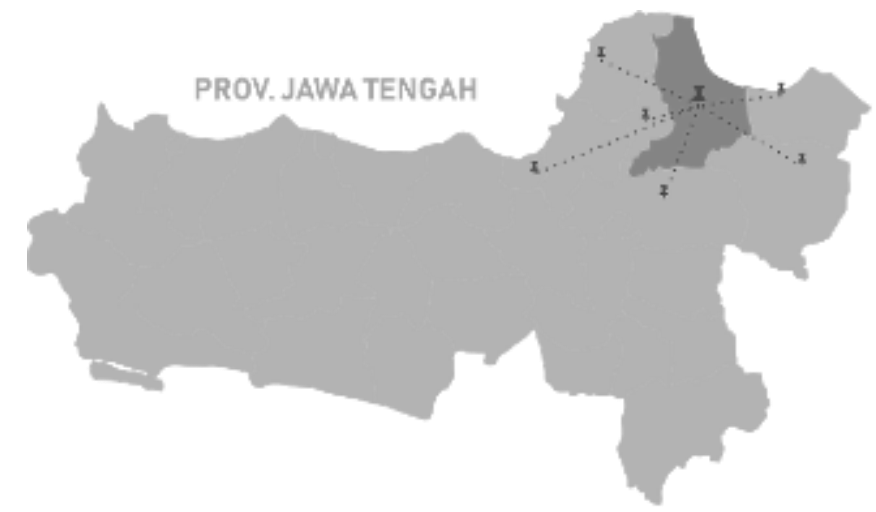

Gambar 3. Kabupaten Pati sebagai node beberapa kota sekitarnya.

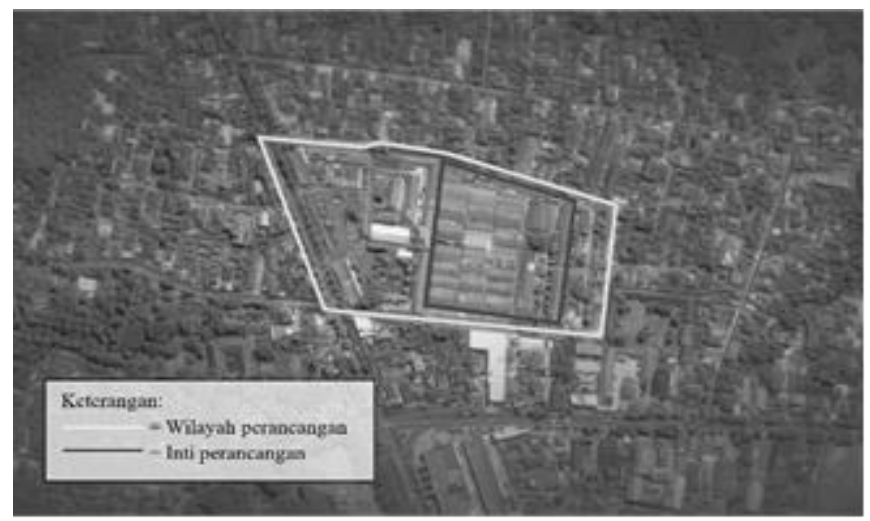

Gambar 4. Lahan Pasar Tradisional Puri Pati.

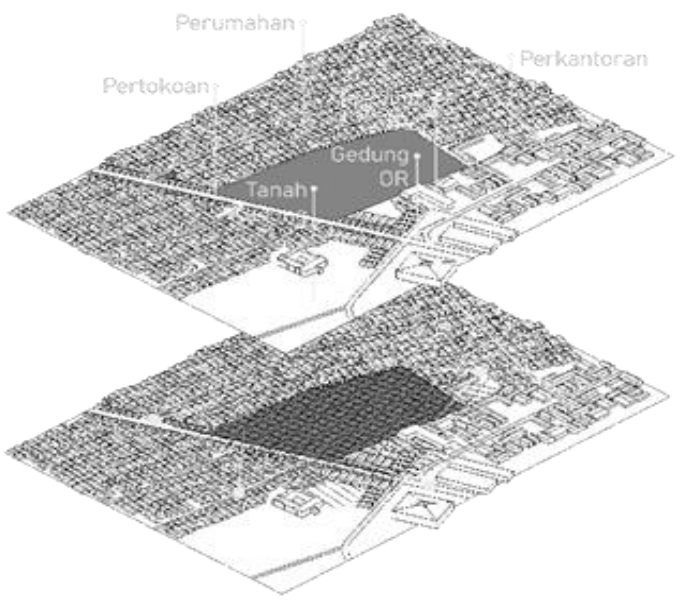

Gambar 5. Potensi view Pasar Tradisional Puri Kab. Pati.

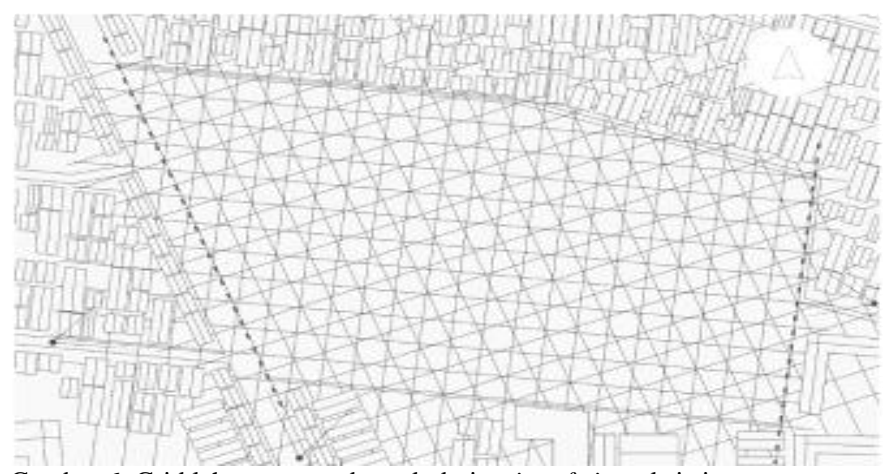

Gambar 6. Grid lahan yang terbentuk dari point of view eksisting.

\section{Permasalahan Desain}

Permasalahan desain pun muncul mengenai bagaimana skala ruang pada pasar tradisional dapat menjadi sebuah pemicu timbulnya interaksi yang positif, dimulai dari jalur-jalur sirkulasi hingga ruang-ruang yang sering dilalui oleh pengguna. Sehingga kondisi demikian berpengaruh terhadap proses sosial yang arif dalam pembentukan perilaku dan karakter pribadi antar perorang.

Ditambah dengan karakter Kab. Pati yang mempunyai 3 julukan unik menjadi potensi penting sebagai tantangan tersendiri yang patut un tuk direspon secara arsitektural melalui pengkondisian pasar tradisional tersebut.

1) Kota Pensiunan

- Lansia yang tidak produktif

- Dicoba untuk diaktifkan kembali

- Dengan fasilitas kegiatan olah raga

2) Kota Karaoke

- Hiburan malam yang bernilai negatif

- Diidentifikasi nilai (+) (-)

- Memberikan hiburan malam pengganti seperti wayang/live music (malam) \& karaoke keluarga

3) Kota Paranormal

- Masyarakat yang masih percaya tahayul

- Diidentifikasi nilai (+) (-)

- Dicerahkan melalui aktivitas public seperti coworking \& perpus kecil

- Ditingkatkan eksistensi pusaka lokal melalui galeri 
Tabel 1.

Data pedagang Pasar Tradisional Puri Pati

\begin{tabular}{|c|c|c|c|c|c|}
\hline No. & Jenis & Jumlah & No. & Jenis & Jumlah \\
\hline 1. & Aksesoris & 39 & 19. & Pakan Ternak & 2 \\
\hline 2. & Bank & 8 & 20. & Beras & 8 \\
\hline 3. & Counter Hp & 4 & 21. & Bumbu & 64 \\
\hline 4. & Elektronik & 7 & 22. & Gilingan & 6 \\
\hline 5. & Emas-Silver & 166 & 23. & Kacang & 5 \\
\hline 6. & Figura & 3 & 24. & Kelapa & 37 \\
\hline 7. & Jasa Jahit & 12 & 25. & Ketela & 3 \\
\hline 8. & Konveksi & 177 & 26. & Kerupuk & 6 \\
\hline 9. & Kelontong & 63 & 27. & Sayuran & 50 \\
\hline 10. & Kosmetik & 13 & 28. & Sembako & 67 \\
\hline 11. & Pakaian & 98 & 29. & Tahu-Tempe & 35 \\
\hline 12. & Plastik & 25 & 30. & Buah & 70 \\
\hline 13. & Sepatu-Sandal & 80 & 31. & Bunga & 6 \\
\hline 14. & VCD & 11 & 32. & Gerabah & 7 \\
\hline 15. & Lain-lain & 82 & 33. & Roti/Snack & 105 \\
\hline 16. & Ayam & 123 & 34. & Obat & 5 \\
\hline 17. & Daging & 14 & 35. & Warung Makan & 34 \\
\hline 18. & Ikan & 53 & & TOTAL & 1488 \\
\hline & $3 \times 3$ & $2 \times 2$ & & & \\
\hline
\end{tabular}

\section{METODA PERANCANGAN}

Metode desain digunakan sebagai acuan untuk mencapai hasil dari permasalahan desain yang dituju. Terdapat 3 (tiga) metode desain yang digunakan, yakni metode riset, metode perancangan, dan metode formal.

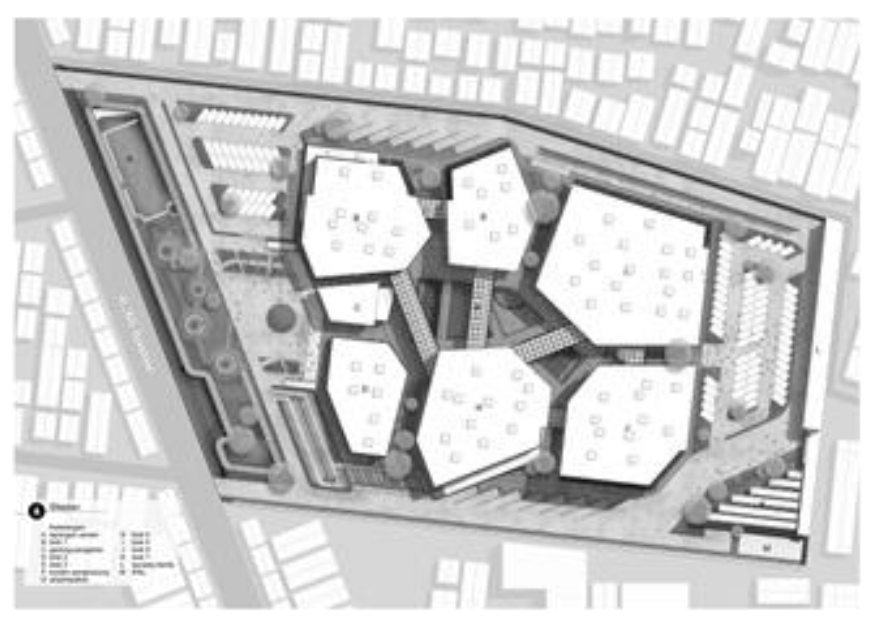

Gambar 7. Siteplan.

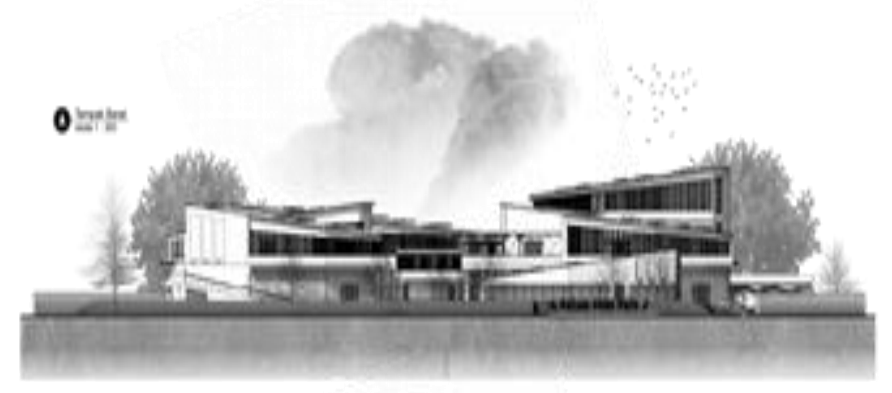

Gambar 8. Tampak barat bangunan.

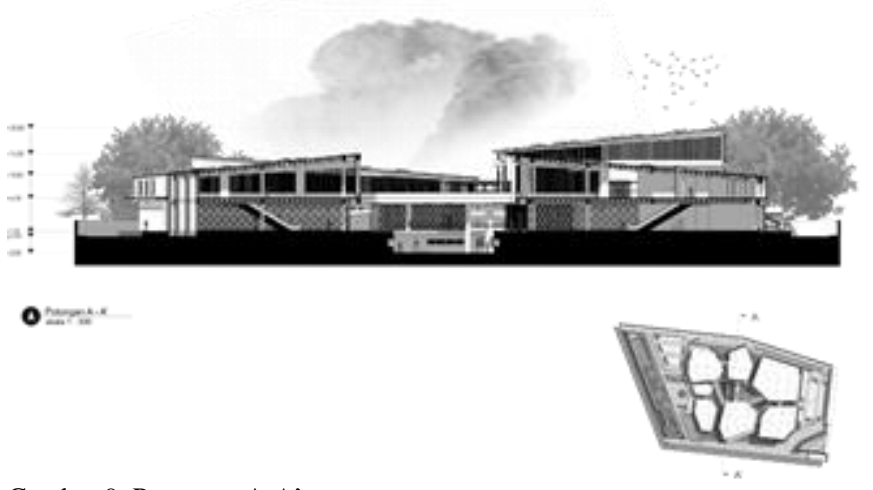

Gambar 9. Potongan A-A'.

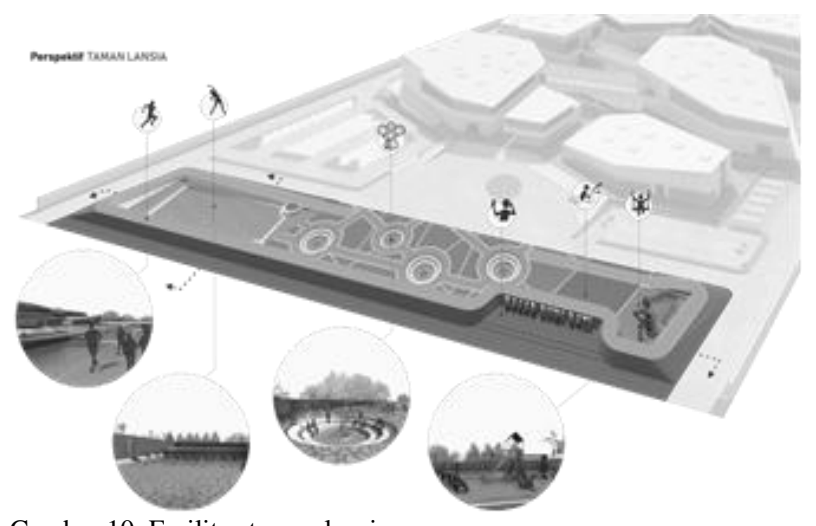

Gambar 10. Fasilitas taman lansia.

\section{A. Metode Riset}

Metode riset yang digunakan adalah metode behavior mapping dari Ittelson, 1970. Berguna untuk menganalisa data dan fakta-fakta yang terjadi pada lapangan melalui pemetaan perilaku [4], berdasarkan:

- Person-Center Maps

Teknik survei perilaku ini menekankan pada pergerakan manusia di periode waktu tertentu. Dari hasil survey terlihat konfigurasi pasar tidak disusun sesusai dengan zona jenis dagang, ini berdampak pada pola pergerakan pengguna yang tidak teratur dan saling berpapasan tak menentu.

- Place-Centered Maps

Teknik survei kehidupan lokasi ini bertujuan untuk mengetahui bagaimana manusia mengatur dirinya dalam suatu lokasi tertentu. Dari hasil survey terlihat pola-pola komunikasi antar pengguna, terjadi proses sosial (interaksi positif). Namun proses ini terjadi hanya pada rentang waktu yang singkat sekitar pukul 05.30 - 09.00 wib, selebihnya pasar mulai terlihat legang dan lambat laun tinggal para pedagang yang melakukan proses sosial. Pasar Puri Pati pada bangunan inti (dalam) dibuka pada pukul 04.30 wib dan ditutup pada pukul 15.30 wib.

- Physycal Trace

Teknis survei kondisi lingkungan bertujuan untuk mendapatkan tanda-tanda yang ditinggalkan pengguna setelah melakukan aktifitas. Dari hasil survey terlihat luasan sirkulasi yang cukup sempit, bila terjadi pergerakan saling berpapasan harus memposisikan diri untuk memiringkan badan guna melewati satu sama lain. Namun hal ini terlihat cukup positif dari kondisi movement tersebut, bahwa dengan adanya kondisi 
demikian (gesekan fisik satu dengan yang lain) menjadi pemicu sebuah proses interaksi secara tidak langsung.

\section{B. Metode Perancangan}

Metode yang digunakan adalah metode Architectural Programming dari Williams M. Pena dalam bukunya Problem Seeking. Metode tersebut dipilih karena model metode program yang dikembangkan berbasis terhadap isu dan fakta lapangan, karena isu dan fakta lapangan [5] yang diangkat merupakan suatu abstraksi terhadap dasar munculnya arsitektur. Metode ini digunakan untuk mempermudah alur berfikir dalam menentukan permasalahan desain yang kemudian ditarik menjadi perwujudan kriteria konsep desain.

\section{Metode Formal}

Metode formal yang digunakan adalah metode grid, dimana grid garis pada lahan akan menentukan setiap tarikan garis rancangan desain (lihat Gambar 6-9). Metode ini lebih kepada eksplorasi sendiri, dilihat dari kondisi/karakter eksisting yang memungkinkan untuk menarik para pengunjung.

\section{HASIL DAN EKSPLORASI}

Adapun tantangan utama tipologi pasar tradisional adalah "dead space" atau area sepi pengunjung. Maka dalam upaya menghindari hal tersebut digunakan beberapa strategi, yakni:

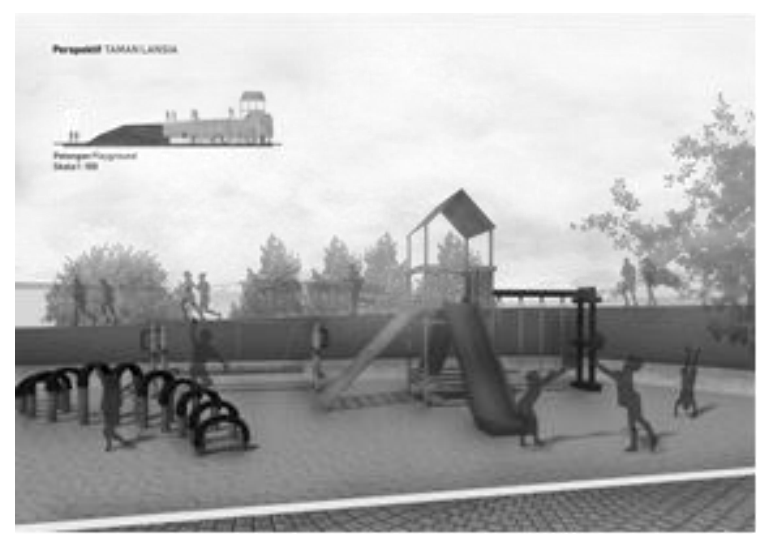

Gambar 11. Playground taman lansia.

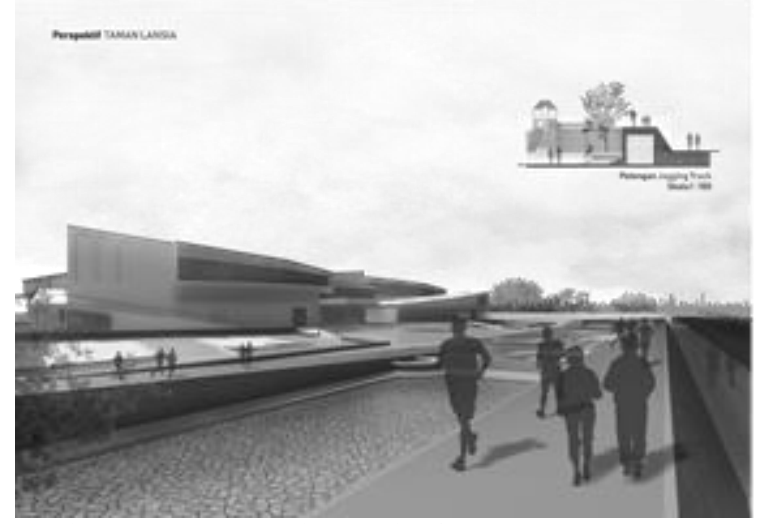

Gambar 12. Jogging track taman lansia.

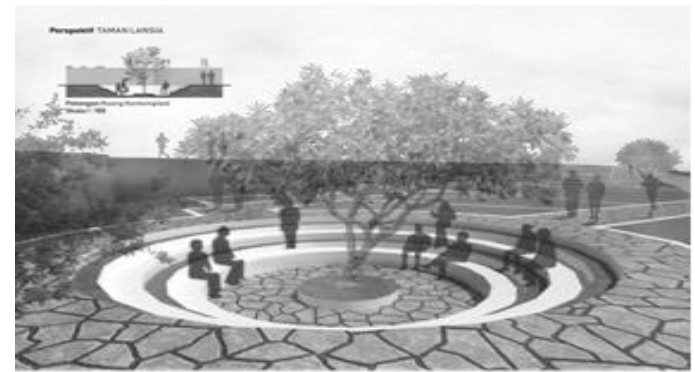

Gambar 13. Ruang kontemplasi taman lansia.

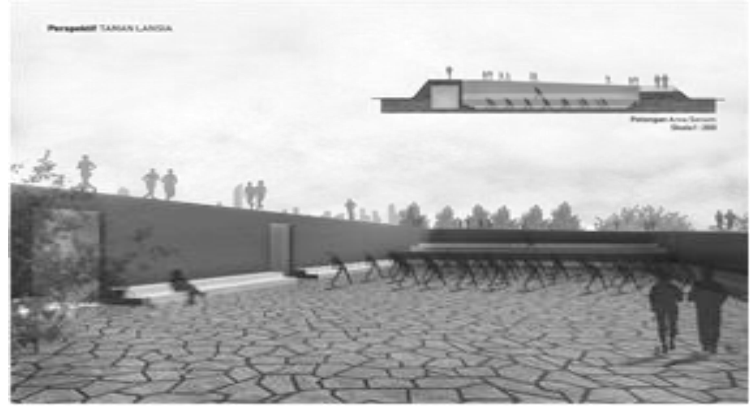

Gambar 14. Lapangan senam taman lansia.

Tabel 2.

\begin{tabular}{|c|c|c|c|c|c|}
\hline \multicolumn{6}{|c|}{ Pembagian blok sesuai dengan jenis dagang [6] } \\
\hline \multicolumn{3}{|c|}{ Pembagian blok sest } & \multicolumn{3}{|c|}{ BLOKII } \\
\hline No. & Jenis & Luasan & No. & Jenis & Luasan \\
\hline 1. & Obat & $5(2 \times 2)$ & 1. & Bank & $8(4 \times 6)$ \\
\hline 2. & Roti/Snack & $105(2 \times 2)$ & 2. & Counter $\mathrm{Hp}$ & $4(3 \times 3)$ \\
\hline 3. & Sayuran & $50(2 \times 2)$ & 3. & Elektronik & $7(3 \times 3)$ \\
\hline 4. & Buah & $70(2 \times 2)$ & 4. & VCO & $11(2 \times 2)$ \\
\hline \multirow{2}{*}{\multicolumn{3}{|c|}{$\begin{array}{l}\text { Kebutuhan Luasan Totat } \\
\frac{1200 \mathrm{~m}^{2}}{2 \text { lantai }}==600 \mathrm{~m}^{2} / \text { lantai }\end{array}$}} & 5. & Warung makan & $8(3 \times 3)$ \\
\hline & & & \multicolumn{3}{|c|}{$\begin{array}{l}\text { Kebutuhan Luasan Total: } \\
.660 \mathrm{~m}^{2}=-320 \mathrm{~m} / \text { lantai } \\
=2 \text { lantai }\end{array}$} \\
\hline \multicolumn{3}{|c|}{ BLOKIII } & \multicolumn{3}{|c|}{ BLOKIV } \\
\hline No. & Jenis & Luasan & No. & Jenis & Luasan \\
\hline 1. & Aksesoris & $39(2 \times 2)$ & 1. & Kelontong & $63(3 \times 3)$ \\
\hline 2. & Emas - Silver & $16(3 \times 3)$ & 2. & Plastik & $25(2 \times 2)$ \\
\hline 3. & Kosmetik & $13(3 \times 3)$ & 3. & Figura & $3(3 \times 3)$ \\
\hline 4. & Bunga & $6(3 \times 3)$ & 4. & Gerabah & $7(3 \times 3)$ \\
\hline 5. & Warung Makan & $7(3 \times 3)$ & 5. & Lain-lain & $82(2 \times 2)$ \\
\hline \multicolumn{3}{|c|}{$\begin{array}{l}\text { Kebutuhan Luasan Total: } \\
\text { - } \\
\text { 2 Lantai } \\
\text { Lantai }\end{array}$} & \multicolumn{3}{|c|}{$\begin{array}{l}\text { Kebutuhan Luasan Total: } \\
=\frac{1800 \mathrm{~m}^{2}}{2 \text { lantai }}\end{array}$} \\
\hline \multicolumn{3}{|c|}{ BLOKV } & \multicolumn{3}{|c|}{ BLOKVI } \\
\hline No. & Jenis & Luasan & No. & Jenis & Luasan \\
\hline 1 & Jasa Jahit & $12(2 \times 2)$ & 1. & Beras & $8(3 \times 3)$ \\
\hline 2. & Konveksi & $177(3 \times 3)$ & 2. & Bumbu & $64(2 \times 2)$ \\
\hline 3. & Pakaian & $98(3 \times 3)$ & 3. & Kacang & $5(2 \times 2)$ \\
\hline 4. & Sepatu-Sandal & $80(2 \times 2)$ & 4. & Kelapa & $37(2 \times 2)$ \\
\hline 5. & Warung Makan & $11(3 \times 3)$ & 5. & Ketela & $3(2 \times 2)$ \\
\hline \multirow{3}{*}{\multicolumn{3}{|c|}{$\begin{array}{l}\text { Kebutuhan Luasan Total: } \\
=4000 \mathrm{~m}^{2}==2000 \mathrm{~m} / \text { lantai } \\
2 \text { lantai }\end{array}$}} & 6. & Sembako & $67(2 \times 2)$ \\
\hline & & & 7. & Tahu Tempe & $35(2 \times 2)$ \\
\hline & & & 8. & Ayam & $57(2 \times 2)$ \\
\hline \multicolumn{3}{|c|}{ BLOK VII } & 9. & Daging & $14(2 \times 2)$ \\
\hline & & & 10. & Ikan & $53(2 \times 2)$ \\
\hline No. & Jenis & Luasan & 11. & Warung Makan & $8(3 \times 3)$ \\
\hline 1. & Gilingan & $2(3 \times 3)$ & \multirow{3}{*}{\multicolumn{3}{|c|}{$\begin{array}{l}\text { Kebutuhan Luasan Totat } \\
=4200 \mathrm{~m}^{2}=.1200 \mathrm{~m}^{2} / \text { lantai } \\
\text { 3lantai }\end{array}$}} \\
\hline 2. & Ayam hidup & $66(2 \times 2)$ & & & \\
\hline 3. & Pakan Ternak & $6(3 \times 3)$ & & & \\
\hline
\end{tabular}




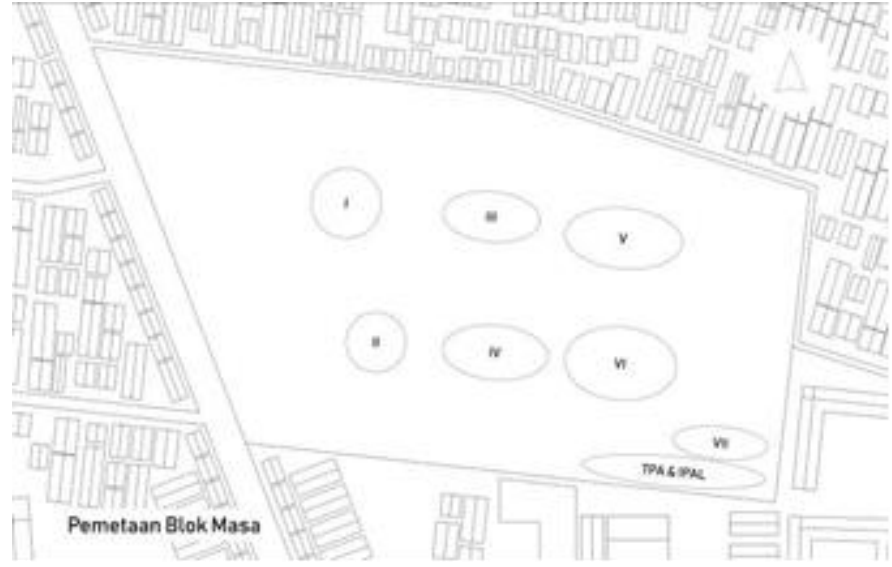

Gambar 15. Tatanan blok masa pada tapak.
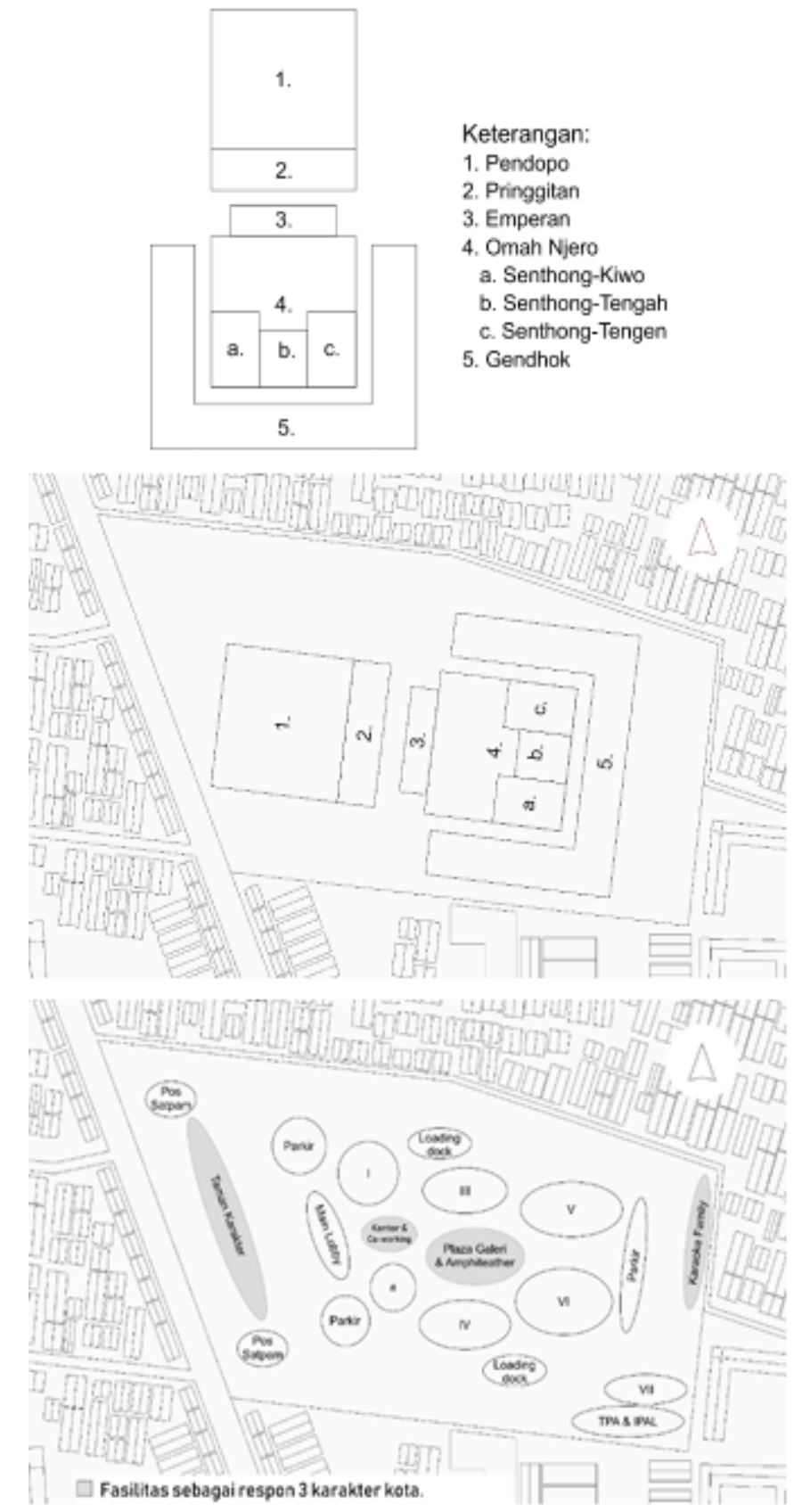

Gambar 16. Organisasi ruang berdasar filosofi rumah jawa.

\section{A. Strategi Zoning System: berdasar jenis dagang}

Perlu upaya mengatur pergerakan pengunjung agar merata. sebagai berikut:

1) Jenis dagang dikelompokkan sesuai dengan karakter dan tingkat keramaian pengunjung menjadi blok-blok dagang.

2) Jenis dagang dengan tingkat keramaian tinggi \& potensi bau ditempatkan di area paling belakang.

3) Jenis dagang dengan tingkat keramaian rendah ditempatkan di area depan.

4) Setidaknya terdapat 2 jenis dagang dengan tingkat keramaian tinggi ditempatkan di area depan sebagai muka keramaian pasar kepada masyarakat. (lihat tabel 2 dan Gambar 15).

\section{B. Strategi Organisasi ruang: berdasar filosofi rumah adat jawa}

Objek rancang kental akan sosial-budaya, maka penataan fasilitas ruang mengadopsi tatanan filosofi "Rumah Adat Jawa Tengah". (lihat Gambar 16)

1) Pendapa, digunakan untuk aktivitas formal diaplikasikan menjadi ruang publik Taman karakter yang berbentuk landscaping terbuka. mewadahi aktivitas lansia dan publik. (lihat Gambar 10-14)

2) Pringgitan, merupakan lorong penghubung yang biasa digunakan untuk pertunjukan wayang kulit / kesenian / kegiatan publik. diaplikasikan menjadi gabungan ruang untuk lansia seperti ruang kontemplasi, ruang senam, dll.

3) Emperan, adalah teras depan dari omah njero sebagai transisi muka. diaplikasikan menjadi transisi untuk menuju bangunan utama. mewadahi area parkir, main lobby dan ruang servis lainnya.

4) Omah njero, adalah unit untuk bertempat tinggal. diaplikasikan menjadi ruang masa keseluruhan bangunan meliputi kantor pengelola, blok-blok masa, dan ruang servis lainnya.

a) Sethong kiwa, digunakan sebagai kamar tidur keluarga atau tempat beras/ alat tani. diaplikasikan menjadi blok ganjil blok I, blok III dan blok V.

b) Senthong tengen, berfungsi sama dengan senthong kiwa. diaplikasikan menjadi blok genap. blok II, blok IV, dan blok VI.

c) Senthong tengah, sering difungsikan menjadi ruang pamer juga ruang sakral. diaplikasikan menjadi ruang publik plaza, galeri, dan amphiteather (live music).

5) Gandhok, bangunan tambahan. diaplikasikan menjadi ruang-ruang servis seperti bongkar muat, parkir belakang, TPA, IPAL, blok VI dan karaoke family.

\section{Strategi Layouting: Voronoi Shape}

Tatanan Masa, menggunakan metode grid dan bentuk dari "Voronoi Shape". Karena Pasar Tradisional layaknya ruang organik yang hidup bagi kota, sekaligus pembentuk karakter kota. Setidaknya terdapat 4 tahap dalam menerapkan bentuk Voronoi ke layout lahan. Sebagai berikut:

1) Menentukan grid lahan yang terbentuk dari point of view eksisting. (lihat Gambar 6) 
2) Menentukan titik dan besaran ruang, sesuai dengan hitungan luasan blok masa per luasan grid $12 \times 12$

3) Menghubungkan setiap titik \& tarik garis tegak lurus dari setiap penghubung.

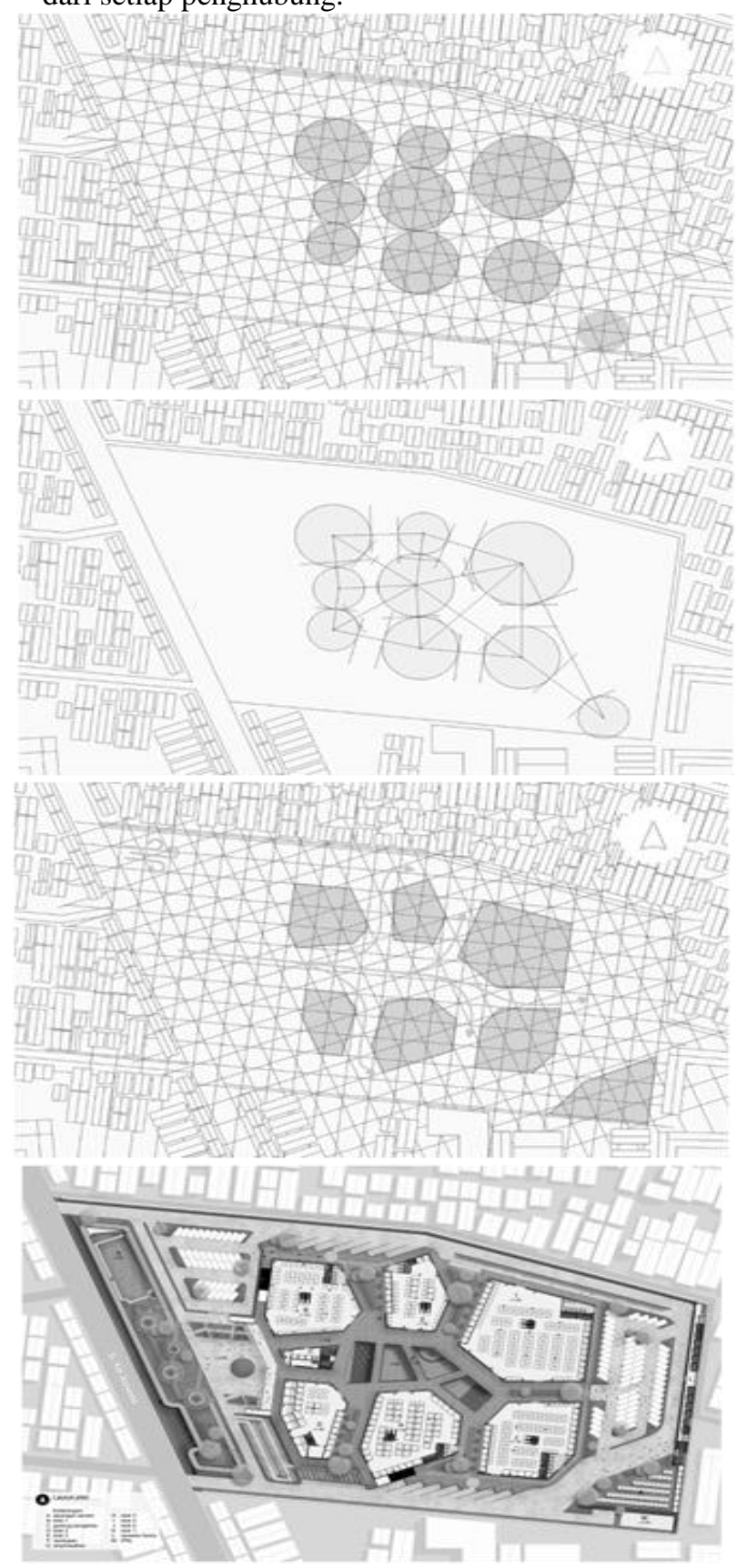

Gambar 17. Penerapan bentuk masa Voronoi shape.

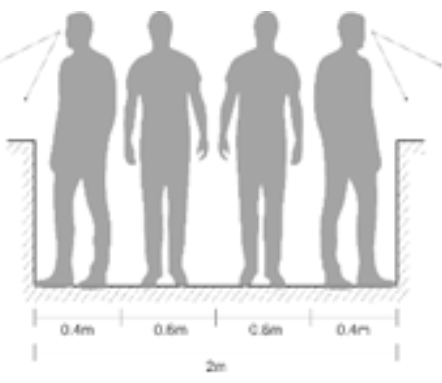

Gambar 18. Lebar sirkulasi yang digunakan.

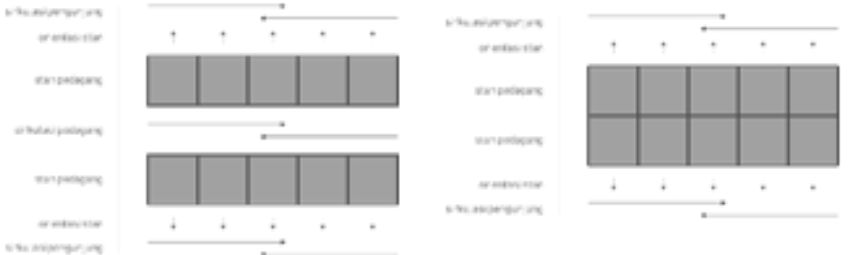

Gambar 19. Konfigurasi unit stan terhadap sirkulasi. (kiri) terdapat sirkulasi khusus untuk pedagang, (kanan) sirkulasi pedagang dihilangkan.
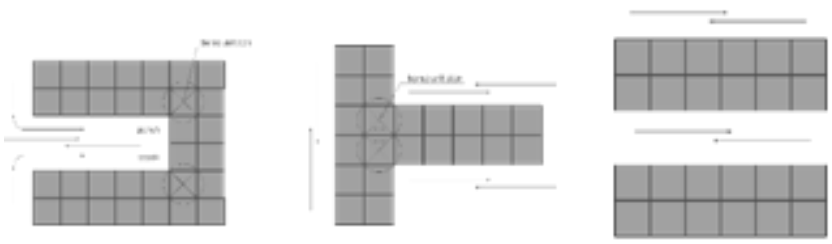

Gambar 19. Konfigurasi blok stan terhadap sirkulasi. (kiri) bentuk U, (tengah) bentuk $\mathrm{T}$, (kanan) bentuk I.

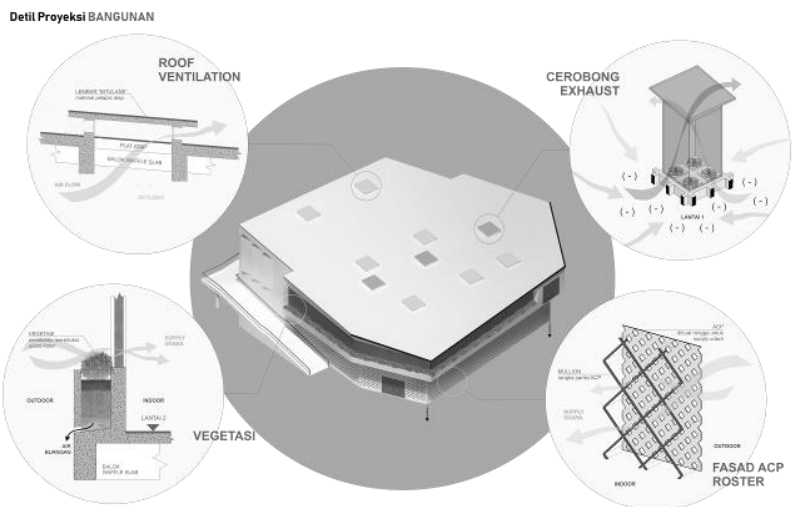

Gambar 20. Detail proyeksi system penghawaan.

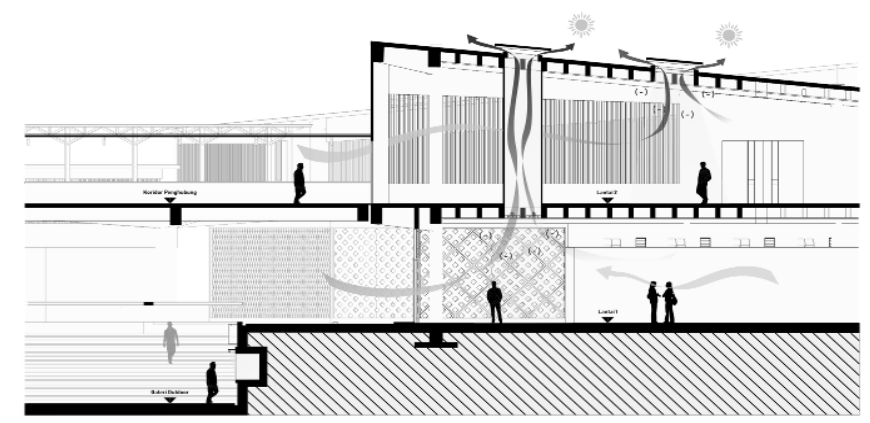

Gambar 21. Gambar potongan teknis.

4) Mengambil bidang dengan menyesuaikan garis potong dan arah angin. Memberikan konsekuensi ruang - ruang saling berhadapan /berinteraksi. (lihat Gambar 7 dan 17)

Dengan konsep Voronoi shape ini dapat mensugesti movement para pengguna untuk memicu interaksi satu sama lain.

\section{Strategi Sirkulasi dan Konfigurasi Stan Dagang}

Dari buku Standar Arsitektur karangan Erns \& Peter Neufert, ukuran standar sirkulasi koridor dalam ruang adalah 
$1.4 \mathrm{~m}-2.4 \mathrm{~m}$ untuk 2 orang berpapasan. Dan ukuran ini menjadi kriteria SNI Pasar Tradisional.

Lebar $2 \mathrm{~m}$ sirkulasi koridor diambil dengan pertimbangan agar pengguna cukup leluasa bergerak dan tidak terlalu berjauhan antar pengguna. Sehingga pengunjung tetap terjaga dalam merasakan kontak fisik agar timbul stimulus untuk berinteraksi satu sama lain. (lihat Gambar 15)

Kemudian untuk tatanan unit stan, telah dilakukan studi sebagai berikut.

Dari dua kemungkinan di atas, opsi satu (kiri) dianggap tidak efisien karena boros tempat serta tidak ada pembauran terhadap pengunjung dan pedagang. Sehingga opsi dua (kanan) yang terpilih. (lihat Gambar 18)

Dari tiga kemungkinan di atas, opsi satu (kiri) dianggap tidak efisien karena boros tempat serta sirkulasi pengunjung akan macet penuh di area dalam, opsi dua (tengah) masih terdapat stan yang tidak mempunyai orientasi. Sehingga opsi tiga (kanan) yang terpilih. (lihat Gambar 19)

\section{E. Strategi Penghawaan Alami}

Karena pasar tradisional hanya berfungsi setengah hari, maka blok masa tidak menggunakan system pendinginan aktif (Air Conditioner). Adapun upaya yang dilakukan dengan menggunakan fasad berpori agar mudah terjadinya cross ventilation (pengudaraan silang). (lihat Gambar 20)

Fasad berpori pada lantai 1 menggunakan ACP (alumunium Composit Panel) yang sudah di-custom membentuk pattern lubang-lubang prisma representasi dari batik kabupaten Pati. Sedangkan pada lantai 2-3 menggunakan kisi-kisi kayu yang dipasang sejajar secara vertikal berjarak $10 \mathrm{~cm}$, ditambah lubang-lubang pada atap (roof ventilation) untuk mempercepat pengudaraan silang juga untuk pencahayaan alami bangunan. Penyediaan tanaman hias pada lantai 2-3 pun berguna untuk mereduksi udara kotor dari luar. (lihat Gambar 21)

Selain itu karena blok masa terdapat 2-3 lantai, pada lantai 1 diberikan mesin cerobong exhaust untuk menyedot udara kotor pada bangunan menerus keluar.

\section{KESIMPULAN}

Pasar tradisional adalah ruang sosial sekaligus ruang kota yang masih kental/sarat akan realisasi proses interaksi yang sebenarnya, maka perlu kita jaga dalam membentuk karakter kota yang arif, humanis, nan santun.

Merancang arsitektur tipologi pasar tradisional tidaklah mudah seperti merancang bangunan biasa. Perlu upaya dalam menjaga keholistikan dari segala aspek, karena kompleksitas pasar tradisional menjadi salah satu penggerak utama peradaban kota. Dimana bukan melulu aspek ekonomi yang terkandung, melainkan sosial, budaya, agama, ras, dan berbagai macam teraduk dalam keharmonisan. Tipologi inilah yang masih membawa nilai-nilai kebudayaan yang hak dari masa ke masa.

Dengan konsep synomorphy yang diterapkan pada re-design pasar tradisional puri pati, diharapkan dapat lebih meng-create pola perilaku masyarakat pati dalam merespon 3 julukan yang terkonotasi negatif saat ini.

\section{DAFTAR PUSTAKA}

[1] K. Elly, M, Abdul and E. R, Ilmu Sosial Budaya Dasar. Jakarta: Prenada Media, 2006.

[2] Laurens and J. Marcella, Arsitektur dan Perilaku Manusia. Jakarta: Grasindo, 2004.

[3] T. Hidjaz, "Interaksi Perilaku dan Suasana Ruang di Perkantoran Kasus di 2 lokasi Kantor Pusat PT. Telkom, Bandung," J. Itenas Rekarupa, vol. 1, no. 1, pp. 13-24, 2011.

[4] H. M. Proshanky, W. H. Ittelson, and L. G. Rivlin, Environmental psychology: People and their physical settings, 2nd ed. New York: Holt, Rinehart \& Winston, 1976.

[5] W. M. Pena and et al, Problem Seeking - an Architectural Programming Primer. New York: John Wiley \& Sons Inc, 2001.

[6] Disperindag Kab. Pati, "Laporan Data Pedagang," 2017. [Online]. Available:

http://www.pasar.simpadapati.com/laporan2.php?op=puri. [Accessed: 26-Sep-2017]. 